\title{
Erratum to: Salt or Sludge? Exploring Preferences for Potable Water Sources
}

\author{
Fiona L. Gibson · Michael Burton
}

Published online: 12 October 2013

C) Springer Science+Business Media Dordrecht 2013

\section{Erratum to: Environ Resource Econ DOI 10.1007/s10640-013-9672-9}

The authors would like to point out that the 4th line of equation 8 should read

$$
\begin{array}{ll}
P\{1 / 1\}^{+}=1-\Phi\left(\alpha^{+}+\beta^{+} A_{u}\right) & \text { if } A>0 \\
P\{0 / 0\}^{+}=\Phi\left(\alpha^{+}+\beta^{+} A_{d}\right) & \text { if } A>0 \\
P\{1 / 0\}^{+}=\Phi\left(\alpha^{+}+\beta^{+} A_{u}\right)-\Phi\left(\alpha^{+}+\beta^{+} A\right) & \text { if } A>0 \\
P\{0 / 1\}^{+}=\Phi\left(\alpha^{+}+\beta^{+} A\right)-\Phi\left(\alpha^{+}+\beta^{+} A_{d}\right) & \text { if } A>0
\end{array}
$$

The online version of the original article can be found under doi:10.1007/s10640-013-9672-9.

\section{F. L. Gibson $(\bowtie)$}

Centre for Environmental Economics and Policy, School of Agricultural and Resource Economics, University of Western Australia, 35 Stirling Highway, Crawley, WA 6009, Australia

e-mail: fiona.gibson@uwa.edu.au

\section{Burton}

School of Agricultural and Resource Economics, University of Western Australia, 35 Stirling Highway, Crawley, WA 6009, Australia

e-mail: michael.burton@uwa.edu.au 